\title{
The Reflux Symptoms Before and After Peroral Endoscopic Myotomy of Chinese Patients With Achalasia
}

\author{
Ying Xu, Yan Wang, Yun Bao, Ting Yu, Yurong Tang, Lin Lin, and Liuqin Jiang* \\ Department of Gastroenterology, the First Affiliated Hospital of Nanjing Medical University, Nanjing; China
}

\section{Background/Aims}

Achalasia is a rare disease, but the incidence is increasing recently. Peroral esophageal myotomy (POEM) is an effective treatment. Regurgitation is a common symptom before and after POEM. Our aim is to investigate the factors related to preoperative and postoperative reflux symptoms.

\section{Methods}

Our study was retrospective. The achalasia patients diagnosed by high-resolution manometry and gastroscopy were divided into reflux group and non-reflux group before and after POEM, respectively. General information, symptoms, POEM information, and manometric results were compared.

\section{Results}

(1) Ninety-six of 130 patients had reflux symptoms before POEM. The lower esophageal sphincter pressure (LESP) in the reflux group was significantly higher than the non-reflux group $(P=0.023)$, while integrated relaxation pressure (IRP) was similar. The reflux group had longer esophagus than the non-reflux group $(P=0.006)$. Reflux symptoms were not related to subtypes of achalasia. (2) Twenty-five of 84 patients had reflux symptoms after POEM. Postoperative Eckardt scores, LESP, and 4-second IRP (4sIRP) were significantly lower than the preoperative values $(P<0.001)$. The preoperative values and POEM information were similar between the postoperative 2 groups and there was no significant difference in the presence of preoperative reflux symptoms between 2 groups. The postoperative LESP and 4SIRP were similar between the 2 groups, however, the postoperative UESP was significantly higher in the reflux group than the non-reflux group $(P=0.042)$. The non-reflux group had more declines in Eckardt scores and LESP than the reflux group.

\section{Conclusions}

The reflux symptoms of achalasia patients without treatment were mainly due to food retention. The postoperative reflux symptoms were not the sign of the excessive relaxation of lower esophageal sphincter.

(J Neurogastroenterol Motil 2021;27:377-389)

\section{Key Words}

Esophageal achalasia; Esophagogastric junction; Gastroesophageal reflux; Pyloromyotomy

Received: March 21, 2020 Revised: None Accepted: January 2, 2021

(a) This is an Open Access article distributed under the terms of the Creative Commons Attribution Non-Commercial License (http://creativecommons. org/licenses/by-nc/4.0) which permits unrestricted non-commercial use, distribution, and reproduction in any medium, provided the original work is properly cited.

${ }^{*}$ Correspondence: Liuqin Jiang, MD

Department of Gastroenterology, the First Affiliated Hospital of Nanjing Medical University, Nanjing 210029, China Tel: +86-13951017379, Fax: +86-025-68303472, E-mail: jiangliuqin@163.com 


\section{Introduction}

Achalasia is a rare motility disorder of the esophagus characterized by insufficient esophagogastric junction relaxation and loss of esophageal peristalsis. ${ }^{1}$ The pathogenesis of achalasia remains unclear. The main symptoms are dysphagia, regurgitation, chest pain, and weight loss. ${ }^{2}$

Many patients with achalasia have the symptoms of regurgitation (76-91\%). ${ }^{2}$ The regurgitation may be the retention of undigested food because of the insufficient relaxation of esophagogastric junction. The cause of regurgitation may also be the transient relaxation of the lower esophageal sphincter (LES) or the imbalance between the excitatory and inhibitory neurons of the myenteric plexus. ${ }^{3}$ Many studies have been done to investigate the heartburn of untreated achalsia. ${ }^{4}$ Few studies have focused on the reflux symptom. Fisichella et $\mathrm{al}^{5}$ studied the character of 145 untreated achalasia patients, they found that the reflux of achalasia was not the true reflux. However, Shoenut et $\mathrm{al}^{6}$ found that the $\mathrm{pH}$ monitoring results of untreated achalasia were inconsistent with those of stimulated bacterial fermentation in vitro. So we focused on the reflux symptoms to investigate the factors related to it before treatment.

Peroral esophageal myotomy (POEM) is a recent endoscopic technique and this technique has a consequent risk of gastroesophageal reflux disease (GERD). ${ }^{7}$ Many studies have investigated the gastroesophageal reflux after POEM.$^{7,8}$ However, few studies have focused on the relevant factors of reflux symptoms and the relationship between preoperative and postoperative symptoms. This study aims to evaluate the factors associated with the reflux symptoms before and after POEM and to find the predictors of less reflux symptom after POEM.

\section{Materials and Methods}

\section{Patients}

Our study was a retrospective study. One hundred and ninetynine patients with achalasia diagnosed by HRM in the First Affiliated Hospital of Nanjing Medical University from July 2011 to October 2018 were recruited. Endoscopy and radiology was used to rule out anatomical lesions. Patients with the following conditions were excluded: age less than 18 years or over than 70 years, history of botulinum toxin injection, pneumatic dilatation or surgical myotomy, with systemic diseases that could affect esophageal motility (ie, scleroderma and diabetes), ${ }^{10}$ and consumption of prokinetic medi- cation. ${ }^{10}$ One hundred and thirty patients underwent POEM and were assessed symptoms before POEM. There were 46 patients lost to follow-up, so 84 patients were assessed symptoms after POEM. The study was approved by the Medical Review Ethics Committee of Nanjing Medical University (Approval No. 2019-SR-516).

\section{Symptoms Evaluation}

The symptoms were assessed by questionnaires such as gastroesophageal reflux disease questionnaire (GERDQ) and Eckardt scores. The Eckardt score was used to assess the severity of achalasia ${ }^{11}$ before and after POEM. The GERDQ was used to assess symptoms after POEM. ${ }^{7}$ We defined the preoperative Eckardt scores minus postoperative Eckardt scores for $\triangle$ Eckardt. We assessed the reflux symptoms according to the questionnaires and we defined reflux symptom score greater than or equal to 1 in the Eckardt score as the presence of reflux symptom. Then we divided the patients into 2 groups according to the reflux symptoms.

\section{High-resolution Manometry}

High-resolution manometry (HRM) was used before and after POEM. HRM is the golden standard to diagnose achalasia. All patients were asked to stop taking the medications that may affect esophageal motility a week before the examination. Before the examination, the patient fasted for 12 hours and banned from water for 8 hours. The patient was placed in a semi-decumbent position and a catheter was inserted through the nasal cavity. First, the esophageal resting state was recorded. After that, each patient was required to swallow $5 \mathrm{~mL}$ of water 10 times, with an interval of 2030 seconds between the 2 times. Each time, the patient was required to swallow it as one mouthful as possible. The data was then analyzed. According to the Chicago classification criteria, achalasia was defined as the integrated relaxation pressure (IRP) greater than $15 \mathrm{mmHg}$ and no peristalsis in the esophagus body. According to the patterns of non-peristaltic esophageal pressurization, achalasia could be divided into 3 subtypes: type I, 100\% failed contractions and no esophageal pressurization; type II, no normal peristalsis and $\geq 20 \%$ swallowing with panesophageal pressurization; and type III, no normal peristalsis and $\geq 20 \%$ swallowing with preserved spastic contractions. ${ }^{10,12}$ For comparison, we defined the preoperative lower esophageal sphincter pressure (LESP) minus postoperative LESP for $\triangle \mathrm{LESP}$. We defined the preoperative IRP minus postoperative IRP for $\triangle I R P$.

\section{Peroral Esophageal Myotomy}

POEM was performed by an experienced chief physician. 
POEM was performed in a standard procedure. ${ }^{13}$ Each patient completed preoperative examinations and received general anesthesia. The normal saline + indigo carmine + adrenalin were injected into the submucosa of the wall of esophagus. After the mucosa was fully elevated, a knife was used to cut through the mucosa to form a longitudinal incision, which was then further separated to form a tunnel. After that, a knife was used to cut the esophageal circular muscle and part of the longitudinal muscle along the wall of the esophagus to keep the fibrous membrane intact. The entry site of the tunnel was closed by endoscopic clips.

\section{Statistical Methods}

All statistical analyses were performed using the SPSS version 23.0 (SPSS Inc, Chicago, IL, USA). The normality of data was tested by the Kolmogorov-Smirnov. Independent-samples $t$ test and paired $t$ test were used in normal data, and the values were presented as mean \pm standard deviation in normal data. Chi-square test was used in unordered categorical variables and the data were presented as numbers and percentages. In the case of rank variables or non-normally distributed data, Mann-Whitney $U$ was used, and the rank variables were presented as numbers and percentages, the non-normally distributed data were presented as median and range. A $P$-value $<0.05$ was considered to be statistically significant.

\section{Results}

One hundred and thirty patients with achalasia who underwent POEM were included. Eighty-four patients of them were followed up at least 6 months after POEM, and 32 patients underwent HRM at 6 months after POEM (Fig. 1).

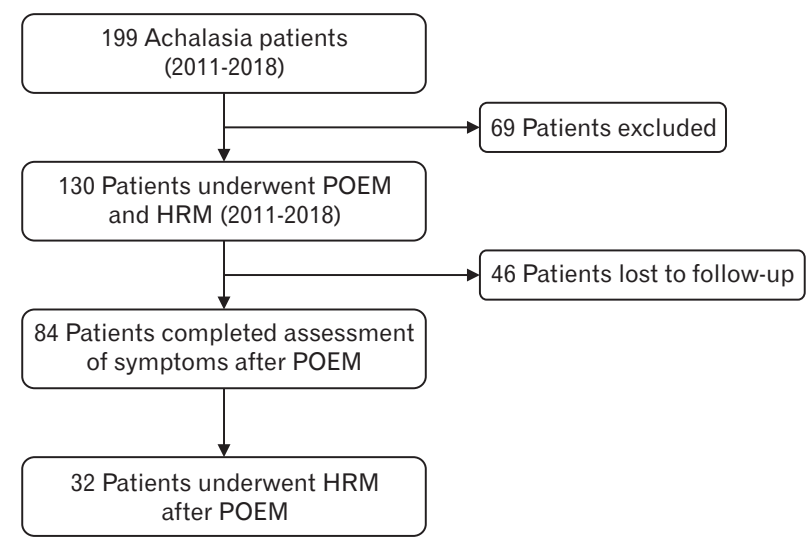

Figure 1. Procedure and follow-up. HRM, high-resolution manometry; POEM, peroral esophageal myotomy.
Table 1. Characteristics of Patients Before Peroral Esophageal Myotomy

\begin{tabular}{|c|c|}
\hline Variables & $\begin{array}{l}\text { Achalasia patients before POEM } \\
\qquad(\mathrm{n}=130)\end{array}$ \\
\hline Gender (male) & $58(44.6)$ \\
\hline Age (yr) & $42.64 \pm 14.10$ \\
\hline $\operatorname{BMI}\left(\mathrm{kg} / \mathrm{m}^{2}\right)$ & $21.37(18.85-24.06)$ \\
\hline \multicolumn{2}{|l|}{ Eckardt scores } \\
\hline \multicolumn{2}{|l|}{ Dysphagia } \\
\hline Never, 0 & $0(0.0)$ \\
\hline Occasional, 1 & $12(9.2)$ \\
\hline Daily, 2 & $39(30.0)$ \\
\hline Every meal, 3 & $79(60.8)$ \\
\hline \multicolumn{2}{|l|}{ Regurgitation } \\
\hline Never, 0 & $34(26.2)$ \\
\hline Occasional, 1 & $64(49.2)$ \\
\hline Daily, 2 & $26(20.0)$ \\
\hline Every meal, 3 & $6(4.6)$ \\
\hline \multicolumn{2}{|l|}{ Chest pain } \\
\hline Never, 0 & $81(62.3)$ \\
\hline Occasional, 1 & $27(20.8)$ \\
\hline Daily, 2 & $14(10.8)$ \\
\hline Every meal, 3 & $8(6.1)$ \\
\hline \multicolumn{2}{|l|}{ Weight loss } \\
\hline No weight loss, 0 & $84(64.6)$ \\
\hline$<5 \mathrm{~kg}, 1$ & $27(20.8)$ \\
\hline $5-10 \mathrm{~kg}, 2$ & $14(10.8)$ \\
\hline$>10 \mathrm{~kg}, 3$ & $5(3.8)$ \\
\hline Total Eckardt scores & $5(4-5)$ \\
\hline \multicolumn{2}{|l|}{ Other symptoms } \\
\hline \multicolumn{2}{|l|}{ Heartburn } \\
\hline Absent & $79(60.8)$ \\
\hline Present & $51(39.2)$ \\
\hline \multicolumn{2}{|l|}{ Nausea } \\
\hline Absent & $82(63.1)$ \\
\hline Present & $48(36.9)$ \\
\hline \multicolumn{2}{|l|}{ Emesis } \\
\hline Absent & $68(52.3)$ \\
\hline Present & $62(47.7)$ \\
\hline \multicolumn{2}{|l|}{ Ructus } \\
\hline Absent & $89(68.5)$ \\
\hline Present & $41(31.5)$ \\
\hline \multicolumn{2}{|l|}{ HRM } \\
\hline $\operatorname{LESP}(\mathrm{mmHg})$ & $34.90(28.20-43.80)$ \\
\hline $\operatorname{IRP}(\mathrm{mmHg})$ & $30.58 \pm 11.30$ \\
\hline \multicolumn{2}{|l|}{ Subtypes } \\
\hline Type I & $15(11.5)$ \\
\hline Type II & $114(87.7)$ \\
\hline Type III & $1(0.8)$ \\
\hline
\end{tabular}

POEM, peroral esophageal myotomy; BMI, body mass index; HRM, highresolution manometry; LESP, resting lower esophageal sphincter pressure; IRP, integrated relaxation pressure.

Values are presented as $\mathrm{n}(\%)$, mean $\pm \mathrm{SD}$, or median (interquartile range). 
Table 2. The Reflux/Non-reflux Group Before Peroral Esophageal Myotomy

\begin{tabular}{|c|c|c|c|}
\hline Variables & Reflux group $(\mathrm{n}=96)$ & Non-reflux group $(\mathrm{n}=34)$ & $P$-value \\
\hline Gender (male/female) & $46 / 50$ & $12 / 22$ & 0.203 \\
\hline Age (yr) & $41.70 \pm 13.80$ & $45.29 \pm 14.70$ & 0.201 \\
\hline $\operatorname{BMI}\left(\mathrm{kg} / \mathrm{m}^{2}\right)$ & $21.10(18.59-24.03)$ & $23.00(20.17-24.12)$ & 0.177 \\
\hline \multicolumn{4}{|l|}{ Eckardt scores } \\
\hline \multicolumn{4}{|l|}{ Dysphagia } \\
\hline Never, 0 & $0(0.0)$ & $0(0.0)$ & \\
\hline Occasional, 1 & $10(10.4)$ & $2(5.9)$ & \\
\hline Daily, 2 & $31(32.3)$ & $8(23.5)$ & \\
\hline Every meal, 3 & $55(57.3)$ & $24(70.6)$ & 0.166 \\
\hline \multicolumn{4}{|l|}{ Chest pain } \\
\hline Never, 0 & $61(63.5)$ & $20(58.8)$ & \\
\hline Occasional, 1 & $21(21.9)$ & $6(17.6)$ & \\
\hline Daily, 2 & $10(10.4)$ & $4(11.8)$ & \\
\hline Every meal, 3 & $4(4.2)$ & $4(11.8)$ & 0.422 \\
\hline \multicolumn{4}{|l|}{ Weight loss } \\
\hline No weight loss, 0 & $59(61.5)$ & $25(73.5)$ & \\
\hline$<5 \mathrm{~kg}, 1$ & $22(22.9)$ & $5(14.7)$ & \\
\hline $5-10 \mathrm{~kg}, 2$ & $10(10.4)$ & $4(11.8)$ & \\
\hline$>10 \mathrm{~kg}, 3$ & $5(5.2)$ & $0(0.0)$ & 0.211 \\
\hline Total Eckardt scores & $5(4-6)$ & $4(3-5)$ & $<0.01^{\mathrm{a}}$ \\
\hline \multicolumn{4}{|l|}{ Other symptoms } \\
\hline \multicolumn{4}{|l|}{ Heartburn } \\
\hline Absent & $52(54.2)$ & $27(79.4)$ & \\
\hline Present & $44(45.8)$ & $7(20.6)$ & $0.010^{\mathrm{b}}$ \\
\hline \multicolumn{4}{|l|}{ Nausea } \\
\hline Absent & $58(60.4)$ & $24(70.6)$ & \\
\hline Present & $38(39.6)$ & $10(29.4)$ & 0.291 \\
\hline \multicolumn{4}{|l|}{ Emesis } \\
\hline Absent & $48(50.0)$ & $20(58.8)$ & \\
\hline Present & $48(50.0)$ & $14(41.2)$ & 0.376 \\
\hline \multicolumn{4}{|l|}{ Ructus } \\
\hline Absent & $58(60.4)$ & $31(91.2)$ & \\
\hline Present & $38(39.6)$ & $3(8.8)$ & $0.002^{\mathrm{a}}$ \\
\hline \multicolumn{4}{|l|}{ HRM } \\
\hline LES center (distance from nostrils, $\mathrm{cm}$ ) & $47.00(44.00-48.95)$ & $44.20(43.00-46.00)$ & $0.020^{\mathrm{b}}$ \\
\hline Proximal LES (distance from nostrils, $\mathrm{cm}$ ) & $44.90 \pm 3.38$ & $43.45 \pm 3.20$ & $0.044^{\mathrm{b}}$ \\
\hline Length of LES (cm) & $3.30(3.00-4.00)$ & $3.60(3.10-4.10)$ & 0.311 \\
\hline Length of esophageal $(\mathrm{cm})$ & $27.90(26.00-29.00)$ & $25.80(24.00-27.35)$ & $0.006^{\mathrm{a}}$ \\
\hline $\operatorname{LESP}(\mathrm{mmHg})$ & $38.67 \pm 15.86$ & $33.02 \pm 9.70$ & $0.023^{\mathrm{b}}$ \\
\hline $\operatorname{IRP}(\mathrm{mmHg})$ & $31.00 \pm 12.30$ & $29.00 \pm 7.60$ & 0.288 \\
\hline \multicolumn{4}{|l|}{ Subtypes } \\
\hline Type I & $13(13.5)$ & $2(5.9)$ & \\
\hline Type II & $82(85.4)$ & $32(94.1)$ & \\
\hline Type III & $1(1.0)$ & $0(0.0)$ & 0.521 \\
\hline
\end{tabular}

${ }^{\mathrm{a} P}<0.01,{ }^{\mathrm{b}} \mathrm{P}<0.05$.

BMI, body mass index; HRM, high-resolution manometry; LES, lower esophageal sphincter; LESP, lower esophageal sphincter pressure; IRP, integrated relaxation pressure.

Values are presented as $\mathrm{n}$, mean $\pm \mathrm{SD}$, median (interquartile range), or $\mathrm{n}(\%)$. 


\section{Characteristics of Patients Before Peroral Esophageal Myotomy}

Ninety-six of 130 patients had symptoms of regurgitation, 64 patients had the regurgitation symptom occasionally, 26 had the regurgitation symptom daily, and 6 had the regurgitation symptom every meal. The median total Eckardt score was 5 points. Some patients had other symptoms such as chest pain, weight loss, heart burn and so on. One hundred and fourteen had type II achalasia, 15 had type I achalasia, and only 1 person had type III achalasia (Table 1).

\section{The Reflux/Non-reflux Group Before Peroral Esophageal Myotomy}

We divided the 130 patients into 2 groups according to the reflux symptoms before POEM (Table 2). No significant difference was found in age, gender, and body mass index between 2 groups $(P>0.05)$. In terms of symptoms, dysphagia, chest pain and weight loss were similar between 2 groups $(P>0.05)$. Those with reflux symptoms were more likely to have heartburn and ructus. The reflux group had higher Eckardt scores than the nonreflux group $(P<0.01)$. In addition, the reflux group had longer esophagus than the other group $(P=0.006)$. The LESP in reflux group was significantly higher than the non-reflux group (38.67 \pm $15.86 \mathrm{mmHg}$ vs $33.02 \pm 9.7 \mathrm{mmHg}, P=0.023)$. The IRP was similar between 2 groups $(31 \pm 12.3 \mathrm{mmHg}$ vs $29 \pm 7.6 \mathrm{mmHg}$, $P=0.288)$. There was no significant difference in the composition of the 3 subtypes between the 2 groups $(P=0.521)$.

\section{The Reflux/Non-reflux Group After Peroral Esophageal Myotomy}

We compared preoperative and postoperative differences in 84 follow-up patients (Fig. 2). Postoperative median Eckardt scores, median LESP, and mean 4-second IRP (4sIRP) were significantly lower compared to the preoperative values $(P<0.001)$.

We divided patients into 2 groups according to the postoperative reflux symptoms, regardless of preoperative symptoms. The preoperative values were similar between the reflux group and the non-reflux group after POEM $(P>0.05)$. In addition, there was no significant difference in the presence of preoperative reflux symptoms between 2 groups (Table 3). No significant difference was found in tunnel length and myotomy length of POEM between 2 groups. We also compared the postoperative values between 2 groups (Table 3). The reflux group had higher Eckardt scores and GERDQ scores than the non-reflux group $(P<$ 0.01 ). The postoperative median LESP and mean 4sIRP were similar between the 2 groups, however, the mean UES pressure was significant higher in the reflux group than the other group $(71.4 \pm 19.1 \mathrm{mmHg}$ vs $53.96 \pm 23.68 \mathrm{mmHg}, P=0.042)$. Postoperative median Eckardt scores, median LESP, and mean 4sIRP were significantly lower compared to the preoperative values in each group $(P<0.001)$ (Fig. 3). We also compared the $\triangle$ Eckardt, $\triangle \mathrm{LESP}$, and $\triangle \mathrm{IRP}$ between the 2 groups. The $\triangle \mathrm{IRP}$ was similar between the reflux group and non-reflux group. The $\triangle$ Eckardt and $\triangle \mathrm{LESP}$ were different between the 2 groups $(P$ $<0.05$ ), and the non-reflux group had greater reductions in these 2 values.

\section{The Relationship Between Preoperative and Postoperative Reflux Symptom}

Then, to figure out the relationship between preoperative and postoperative reflux symptoms, we divided the patients with preoperative reflux symptoms into the group with postoperative reflux
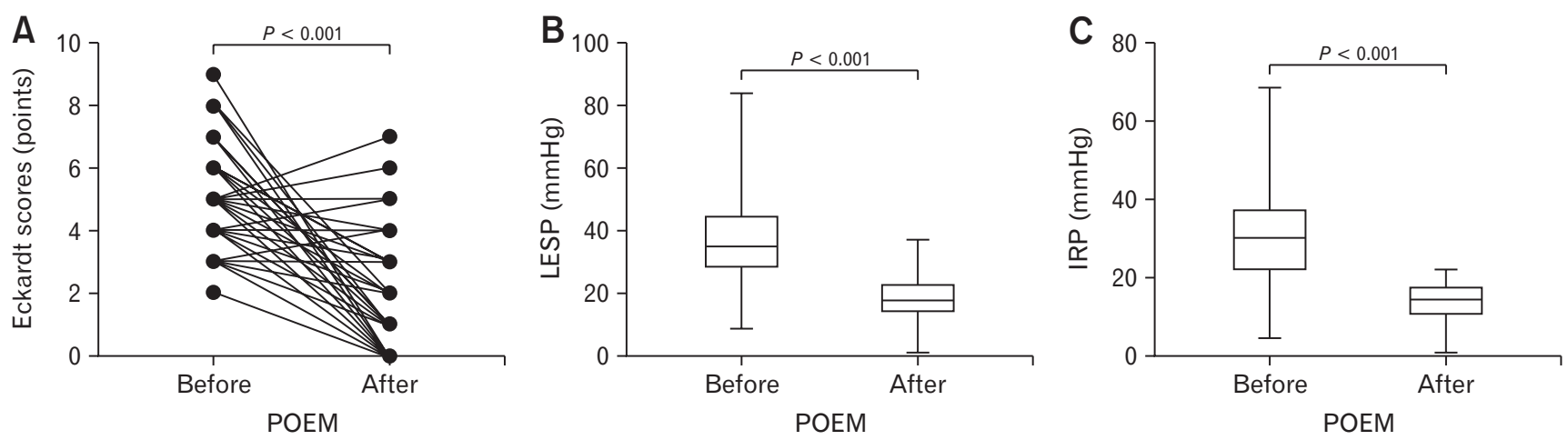

Figure 2. The values before and after peroral esophageal myotomy (POEM) in all patients. (A) The preoperative and postoperative comparison of Eckardt scores in all patients. (B) The preoperative and postoperative comparison of lower esophageal sphincter pressure (LESP) in all patients. (C) The preoperative and postoperative comparison of integrated relaxation pressure (IRP) in all patients. 
Table 3. The Reflux/Non-reflux Group After Peroral Esophageal Myotomy

\begin{tabular}{|c|c|c|c|}
\hline Variables & Reflux group $(\mathrm{n}=25)$ & Non-reflux group $(\mathrm{n}=59)$ & $P$-value \\
\hline Gender (male/female) & $12 / 13$ & $30 / 29$ & 0.811 \\
\hline Age (yr) & $44.61 \pm 15.77$ & $41.40 \pm 11.57$ & 0.303 \\
\hline $\operatorname{BMI}\left(\mathrm{kg} / \mathrm{m}^{2}\right)$ & $22.20(19.50-24.50)$ & $21.50(18.70-23.90)$ & 0.594 \\
\hline \multicolumn{4}{|l|}{ Before POEM } \\
\hline \multicolumn{4}{|l|}{ Regurgitation } \\
\hline Absent & $6(24.0)$ & $15(25.4)$ & \\
\hline Present & $19(76.0)$ & $44(74.6)$ & 0.890 \\
\hline Total Eckardt scores & $5(4-6)$ & $5(3-5)$ & 0.825 \\
\hline \multicolumn{4}{|l|}{ HRM } \\
\hline Length of esophageal (cm) & $27.20 \pm 2.35$ & $27.37 \pm 2.60$ & 0.802 \\
\hline $\operatorname{LESP}(\mathrm{mmHg})$ & $34.50(27.40-48.10)$ & $35.20(28.15-44.25)$ & 0.745 \\
\hline $\mathrm{UESP}(\mathrm{mmHg})$ & $71.30(60.00-97.75)$ & $64.40(39.45-83.05)$ & 0.083 \\
\hline IRP (mmHg) & $31.20 \pm 11.50$ & $29.10 \pm 10.60$ & 0.457 \\
\hline \multicolumn{4}{|l|}{ Subtypes } \\
\hline Type I & $4(16.0)$ & $5(8.5)$ & \\
\hline Type II & $21(84.0)$ & $53(89.8)$ & \\
\hline Type III & $0(0.0)$ & $1(1.7)$ & 0.595 \\
\hline \multicolumn{4}{|l|}{ POEM } \\
\hline Tunnel length (cm) & $14.00(12.25-15.00)$ & $13.00(12.00-14.00)$ & 0.153 \\
\hline Myotomy length $(\mathrm{cm})$ & $11.55 \pm 1.90$ & $10.70 \pm 2.30$ & 0.158 \\
\hline \multicolumn{4}{|l|}{ After POEM } \\
\hline Total Eckardt scores (range) & $3(2-4)$ & $1(0-1)$ & $<0.01$ \\
\hline GERDQ & $7(7-8)$ & $6(6-6)$ & $<0.01$ \\
\hline HRM variables & Reflux group $(\mathrm{n}=13)$ & Non-reflux group $(\mathrm{n}=19)$ & $P$-value \\
\hline Length of esophageal $(\mathrm{cm})$ & $26.90 \pm 2.20$ & $27.10 \pm 2.70$ & 0.851 \\
\hline LESP (mmHg) & $21.03 \pm 7.35$ & $17.10 \pm 7.20$ & 0.137 \\
\hline $\operatorname{UESP}(\mathrm{mmHg})$ & $71.40 \pm 19.10$ & $53.96 \pm 23.68$ & $0.042^{\mathrm{a}}$ \\
\hline IRP (mmHg) & $14.90 \pm 3.50$ & $12.70 \pm 5.20$ & 0.201 \\
\hline$\triangle$ Eckardt scores & $2(-0.5-3)$ & $4(2-5)$ & $<0.01$ \\
\hline$\triangle \mathrm{LESP}(\mathrm{mmHg})$ & $12.30(2.45-16.75)$ & $17.15(12.88-35.15)$ & $0.030^{\mathrm{a}}$ \\
\hline$\triangle \mathrm{IRP}(\mathrm{mmHg})$ & $13.10 \pm 9.15$ & $17.60 \pm 6.57$ & 0.139 \\
\hline
\end{tabular}

${ }^{2} P<0.05$.

BMI, body mass index; POEM, peroral esophageal myotomy; HRM, high-resolution manometry; LESP, lower esophageal sphincter pressure; UESP, upper esophageal sphincter pressure; IRP, integrated relaxation pressure; GERDQ, gastroesophageal reflux disease questionnaire; $\triangle$ Eckardt score $=$ preoperative Eckardt score - postoperative Eckardt score; $\triangle \mathrm{LESP}=$ preoperative LESP - postoperative LESP; $\triangle \mathrm{IRP}$ = preoperative IRP - postoperative IRP.

Values are presented as $\mathrm{n}$, mean $\pm \mathrm{SD}$, median (interquartile range), or $\mathrm{n}(\%)$.

symptoms (reflux ${ }^{+}$reflux $^{+}$) and the group without postoperative reflux symptoms ( reflux $^{+}$reflux $^{-}$). We also divided the patients without preoperative reflux symptoms into the group with postoperative reflux symptoms ( reflux $^{-}$reflux $^{+}$) and the group without postoperative reflux symptoms ( reflux $^{-}$reflux $^{-}$). We compared them respectively.

The preoperative and postoperative values of LESP, IRP, and Eckardt scores were similar in patients who had non-reflux symptoms before POEM and reflux symptoms after POEM (reflux ${ }^{-}$ reflux $^{+}$), while the values before and after POEM were signifi- cantly different in the other 3 groups (Fig. 4 and 5).

There were 19 patients who had reflux symptoms after POEM (reflux ${ }^{+}$reflux $^{+}$) and 44 patients without reflux symptoms (reflux ${ }^{+}$reflux $^{-}$), while they all had reflux symptoms before POEM. The general information, POEM information, LESP, IRP before POEM, and POEM information were similar between 2 groups (Table 4). Among them, 8 patients with postoperative reflux symptoms underwent HRM after POEM, and 14 patients without postoperative reflux symptoms underwent HRM after POEM. The postoperative LESP, IRP, and UESP were similar between 

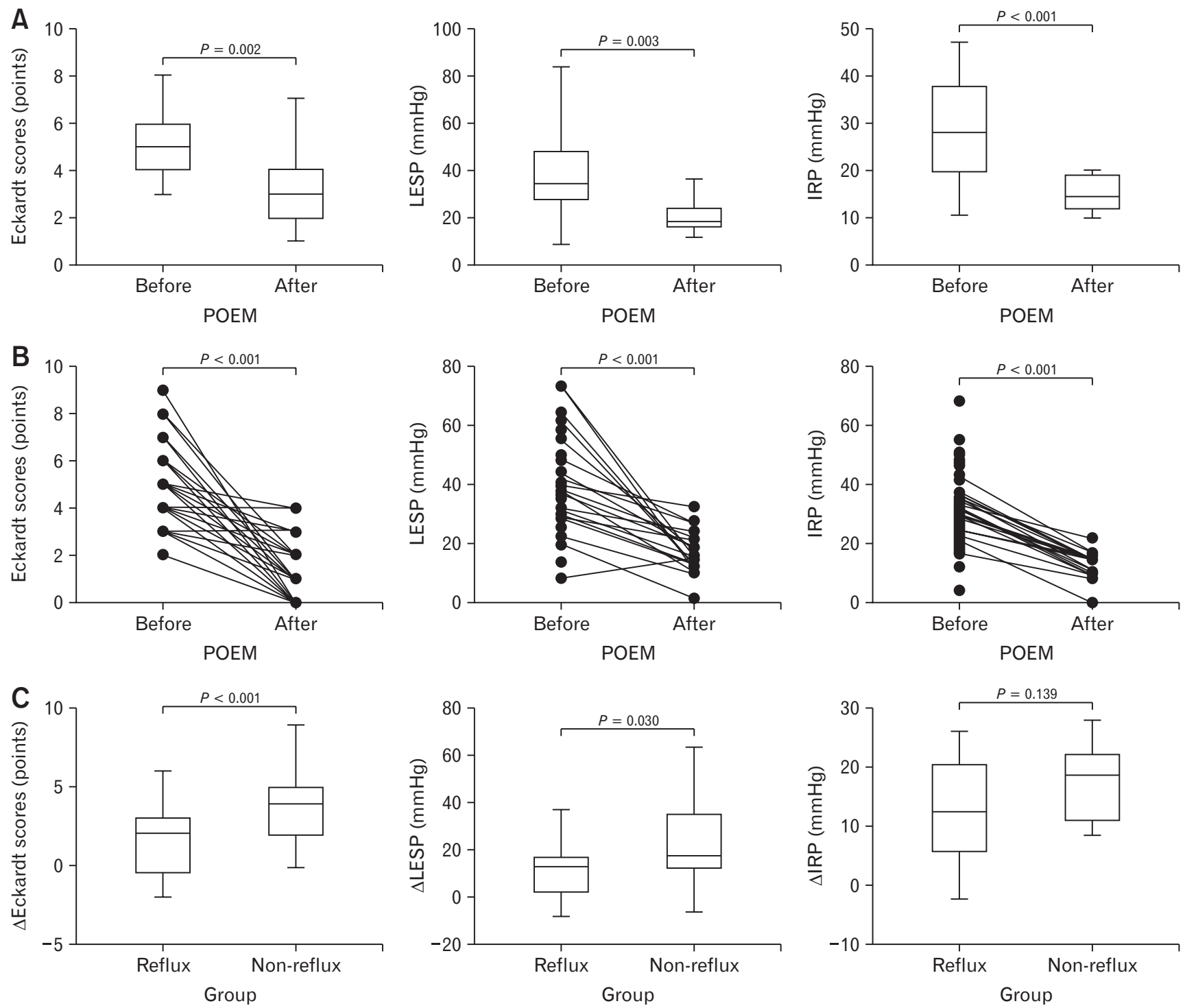

Figure 3. The changes in reflux/non-reflux group after peroral esophageal myotomy (POEM). (A) The preoperative and postoperative comparison of Eckardt scores, lower esophageal sphincter pressure (LESP), and integrated relaxation pressure (IRP) in the patients with reflux symptoms after POEM. (B) The preoperative and postoperative comparison of Eckardt scores, LESP, and IRP in the patients without reflux symptoms after POEM. (C) The comparison of $\triangle \mathrm{Eckardt}, \triangle \mathrm{LESP}$, and $\triangle \mathrm{IRP}$ between 2 groups. $\triangle \mathrm{Eckardt}=$ preoperative Eckardt scores - postoperative Eckardt scores; $\triangle \mathrm{LESP}=$ preoperative LESP - postoperative LESP; $\triangle \mathrm{IRP}=$ preoperative IRP - postoperative IRP.

2 groups. The postoperative Eckardt scores and GERDQ in reflux ${ }^{+}$reflux ${ }^{+}$group were significantly higher than the other group and $\triangle$ Eckardt scores in reflux ${ }^{+}$reflux $^{-}$group was higher (Table 4).

There were 21 patients without reflux symptoms before POEM and among them, 6 patients had postoperative reflux symptoms (reflux ${ }^{-}$reflux ${ }^{+}$) and 15 patients without postoperative reflux symptoms ( reflux $^{-}$reflux $^{-}$). Three of 6 patients underwent HRM and 5 of 15 patients underwent HRM after POEM. The general information, POEM information, and HRM values were similar between 2 groups (Table 5). The patients in reflux ${ }^{-}$reflux $^{+}$ group had higher postoperative Eckardt scores $(P=0.010)$ and GERDQ $(P<0.01)$.

\section{Discussion}

Reflux is a common symptom of achalasia. Many people have reflux symptoms after POEM. The pathogenesis of these 2 refluxes is not necessarily the same. So we should not confuse between 

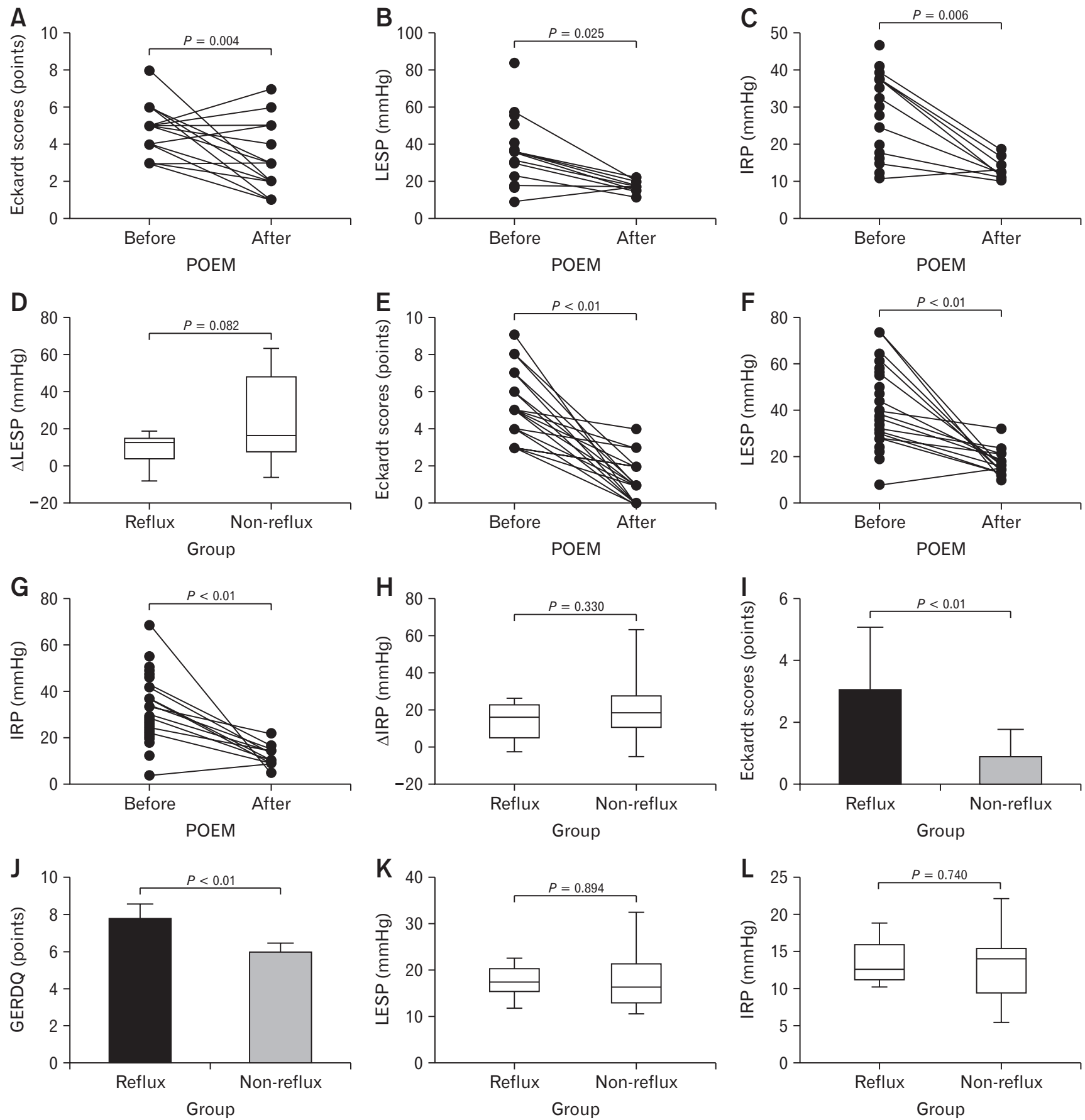

Figure 4. The changes in preoperative reflux and postoperative reflux/non-reflux group. (A-C) The preoperative and postoperative comparison of Eckardt scores, lower esophageal sphincter pressure (LESP), and integrated relaxation pressure (IRP) in preoperative reflux and postoperative reflux groups. (D, H) The comparison of $\triangle \mathrm{LESP}$ and $\triangle \mathrm{IRP}$ between 2 groups. (E-G) The preoperative and postoperative comparison of Eckardt scores, LESP, and IRP in preoperative reflux and postoperative non-reflux groups. (I-L) The comparison of postoperative Eckardt scores, gastroesophageal reflux disease questionnaire (GERDQ), LESP, and IRP between 2 groups. $\triangle$ LESP $=$ preoperative LESP - postoperative LESP; $\triangle$ IRP $=$ preoperative IRP - postoperative IRP. 

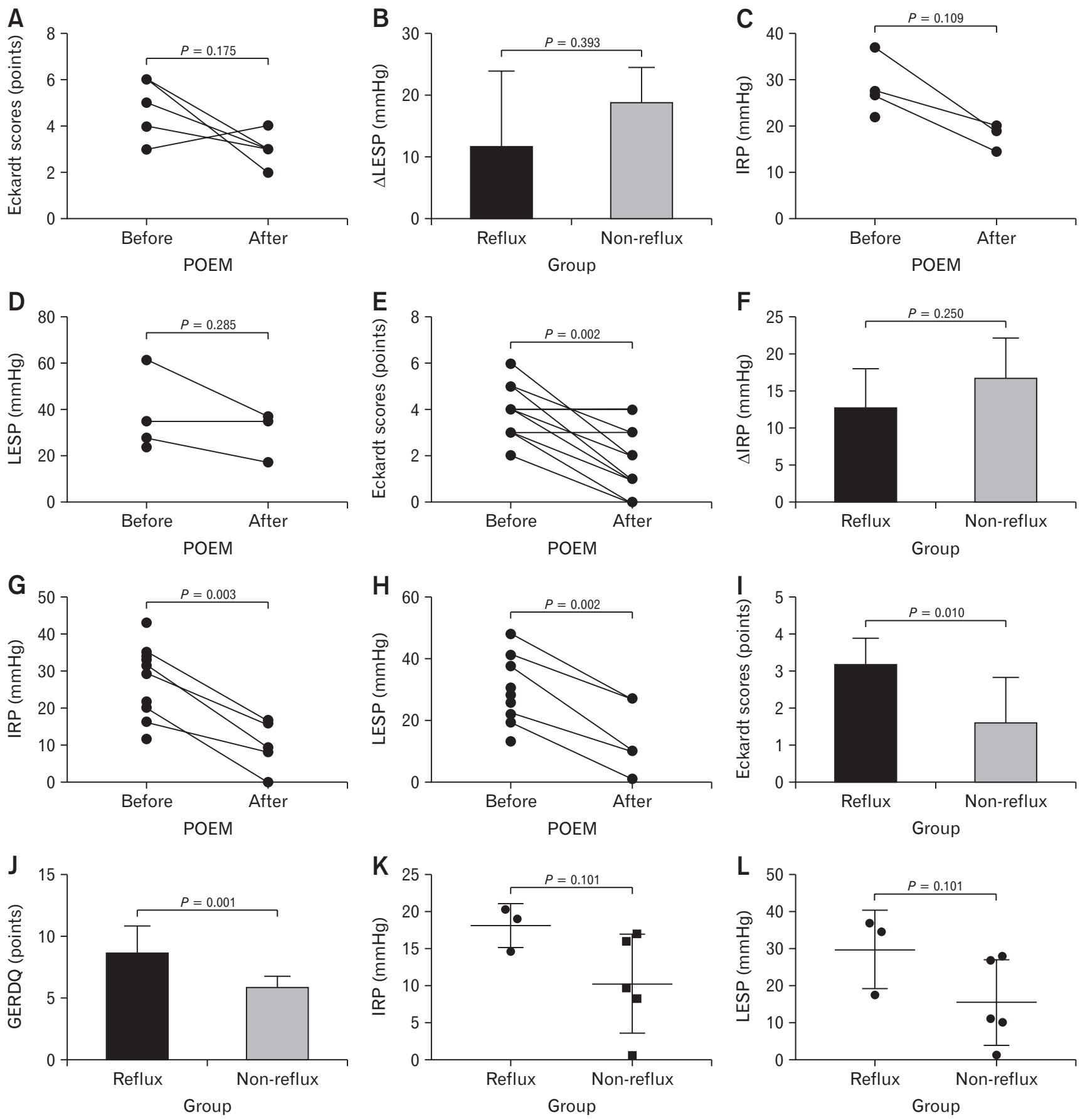

Figure 5. The changes in preoperative non-reflux and postoperative reflux/non-reflux group. (A, C, D) The preoperative and postoperative comparison of Eckardt scores, integrated relaxation pressure (IRP), lower esophageal sphincter pressure (LESP) in preoperative non-reflux and postoperative reflux groups. (B, F) The comparison of $\triangle \mathrm{LESP}$ and $\triangle \mathrm{IRP}$ between 2 groups. $(\mathrm{E}, \mathrm{G}, \mathrm{H}) \mathrm{The}$ preoperative and postoperative comparison of Eckardt scores, IRP, and LESP in preoperative non-reflux and postoperative non-reflux groups. (I-L) The comparison of postoperative Eckardt scores, gastroesophageal reflux disease questionnaire (GERDQ), IRP, and LESP between 2 groups. $\triangle$ LESP $=$ preoperative LESP postoperative LESP; $\triangle \mathrm{IRP}=$ preoperative IRP - postoperative IRP. 
Table 4. The Preoperative Reflux and Postoperative Reflux/Non-reflux Group

\begin{tabular}{|c|c|c|c|}
\hline Variables & $\begin{array}{l}\text { Preoperative reflux and postoperative } \\
\text { reflux group }(\mathrm{n}=19)\end{array}$ & $\begin{array}{l}\text { Preoperative reflux and postoperative } \\
\text { non-reflux group }(\mathrm{n}=44)\end{array}$ & $P$-value \\
\hline Gender (male/female) & $11 / 8$ & $24 / 20$ & 0.806 \\
\hline Age (yr) & $41.58 \pm 12.60$ & $43.25 \pm 15.30$ & 0.677 \\
\hline $\operatorname{BMI}\left(\mathrm{kg} / \mathrm{m}^{2}\right)$ & $22.70(18.90-25.60)$ & $20.88(18.59-23.65)$ & 0.206 \\
\hline \multicolumn{4}{|l|}{ Before POEM } \\
\hline Total Eckardt scores & $5(4-6)$ & $5(4-7)$ & 0.538 \\
\hline \multicolumn{4}{|l|}{ HRM } \\
\hline Length of esophageal $(\mathrm{cm})$ & $28.00 \pm 1.80$ & $27.90 \pm 2.50$ & 0.839 \\
\hline LESP (mmHg) & $37.10 \pm 14.10$ & $39.20 \pm 15.50$ & 0.649 \\
\hline $\operatorname{UESP}(\mathrm{mmHg})$ & $77.60 \pm 28.98$ & $64.20 \pm 28.60$ & 0.120 \\
\hline IRP (mmHg) & $29.40 \pm 11.79$ & $32.30 \pm 12.20$ & 0.398 \\
\hline \multicolumn{4}{|l|}{ Subtypes } \\
\hline Type I & $4(21.1)$ & $4(9.1)$ & \\
\hline Type II & $15(78.9)$ & $39(88.6)$ & \\
\hline Type III & $0(0.0)$ & $1(2.3)$ & 0.466 \\
\hline \multicolumn{4}{|l|}{ POEM } \\
\hline Tunnel length (cm) & $14.00(12.00-15.00)$ & $13.00(12.00-14.00)$ & 0.230 \\
\hline Myotomy length $(\mathrm{cm})$ & $11.00(10.00-12.00)$ & $11.00(9.00-12.00)$ & 0.299 \\
\hline \multicolumn{4}{|l|}{ After POEM } \\
\hline Total Eckardt scores & $2(1-5)$ & $1(0-1)$ & $<0.01$ \\
\hline GERDQ & $7(7-8)$ & $6(6-6)$ & $<0.01$ \\
\hline HRM variables & $\begin{array}{l}\text { Preoperative reflux and postoperative } \\
\text { reflux group }(\mathrm{n}=8)\end{array}$ & $\begin{array}{c}\text { Preoperative reflux and postoperative } \\
\text { non-reflux group }(\mathrm{n}=14)\end{array}$ & $P$-value \\
\hline Length of esophageal $(\mathrm{cm})$ & $27.76 \pm 2.05$ & $26.89 \pm 2.67$ & 0.432 \\
\hline $\operatorname{LESP}(\mathrm{mmHg})$ & $17.38 \pm 3.33$ & $17.68 \pm 5.81$ & 0.894 \\
\hline $\operatorname{UESP}(\mathrm{mmHg})$ & $65.63 \pm 16.20$ & $48.75 \pm 26.87$ & 0.152 \\
\hline IRP (mmHg) & $13.01 \pm 2.70$ & $12.46 \pm 4.17$ & 0.74 \\
\hline$\triangle$ Eckardt scores & $1.7 \pm 2.3$ & $4.3 \pm 1.8$ & $<0.01$ \\
\hline$\triangle \mathrm{LESP}(\mathrm{mmHg})$ & $12.55(3.35-14.88)$ & $16.55(7.90-48.00)$ & 0.082 \\
\hline$\triangle \mathrm{IRP}(\mathrm{mmHg})$ & $16.10(5.20-22.80)$ & $18.10(10.35-24.10)$ & 0.330 \\
\hline
\end{tabular}

BMI, body mass index; POEM, peroral esophageal myotomy; HRM, high-resolution manometry; LESP, lower esophageal sphincter pressure; UESP, upper esophageal sphincter pressure; IRP, integrated relaxation pressure; GERDQ, gastroesophageal reflux disease questionnaire; $\triangle$ Eckardt score $=$ preoperative Eckardt score - postoperative Eckardt score; $\triangle \mathrm{LESP}=$ preoperative LESP - postoperative LESP; $\triangle \mathrm{IRP}=$ preoperative IRP - postoperative IRP.

Values are presented as $\mathrm{n}$, mean $\pm \mathrm{SD}$, median (interquartile range), or $\mathrm{n}(\%)$.

these 2 types. In our study, we addressed symptoms that could not be mistaken for pathological gastroesophageal reflux. We focused on the reflux symptoms. Our aim is to investigate the factors related to the reflux symptoms before and after POEM, we also wanted to figure out the relationship between preoperative reflux symptoms and postoperative reflux symptoms.

Preoperative reflux symptoms were independent of gender, age, and body mass index. The patients with reflux symptoms had higher LESP while the IRP between the 2 groups were similar. This may mean that preoperative reflux symptoms were primarily caused by food retention. Fisichella et $\mathrm{al}^{5}$ studied 145 untreated achalasia patients. In their study, Ambulatory $\mathrm{pH}$ monitoring was performed in 54 patients. The DeMeester score was normal in 47 patients and abnormal in 7 . In these 7 patients, the analysis of the $\mathrm{pH}$ monitoring tracings showed that the abnormal score was caused by false reflux. This conclusion is consistent with our study. In addition, in our study, we found that the patients with reflux symptoms had the longer esophagus. This may indicate that long-term esophageal dysperistalsis and food retention can cause esophageal elongation. It is well known that the achalasia patients often have dilatation of the esophagus. ${ }^{14}$ Few study have reported the extension of esophagus in achalasia. Whether the expansion of the esophagus is accompanied by the extension of the esophagus needs further verification. We also compared the presence and absence of reflux symptoms with 
Table 5. The Preoperative Non-reflux and Postoperative Reflux/Non-reflux Group

\begin{tabular}{|c|c|c|c|}
\hline Variables & $\begin{array}{c}\text { Preoperative non-reflux and } \\
\text { postoperative reflux group }(\mathrm{n}=6)\end{array}$ & $\begin{array}{l}\text { Preoperative non-reflux and } \\
\text { postoperative non-reflux group }(\mathrm{n}=15)\end{array}$ & $P$-value \\
\hline Gender (male/female) & $1 / 5$ & $6 / 9$ & 0.608 \\
\hline Age (yr) & $40.83 \pm 8.33$ & $48.60 \pm 17.02$ & 0.259 \\
\hline $\operatorname{BMI}\left(\mathrm{kg} / \mathrm{m}^{2}\right)$ & $20.90(19.10-22.90)$ & $23.40(20.06-26.83)$ & 0.267 \\
\hline \multicolumn{4}{|l|}{ Before POEM } \\
\hline Total Eckardt scores & $5(3-6)$ & $3(3-4)$ & 0.235 \\
\hline \multicolumn{4}{|l|}{ HRM } \\
\hline Length of esophageal $(\mathrm{cm})$ & $24.28 \pm 1.57$ & $25.99 \pm 2.32$ & 0.148 \\
\hline $\operatorname{LESP}(\mathrm{mmHg})$ & $35.00 \pm 15.30$ & $30.60 \pm 9.70$ & 0.466 \\
\hline Mean UESP $(\mathrm{mmHg})(\mathrm{SD})$ & $71.46 \pm 21.23$ & $61.88 \pm 34.85$ & 0.580 \\
\hline Mean IRP (mmHg)(SD) & $28.20 \pm 5.50$ & $27.30 \pm 8.60$ & 0.833 \\
\hline \multicolumn{4}{|l|}{ Subtypes } \\
\hline Type I & $0(0.0)$ & $1(6.7)$ & \\
\hline Type II & $6(100.0)$ & $14(93.3)$ & \\
\hline Type III & $0(0.0)$ & $0(0.0)$ & 0.714 \\
\hline \multicolumn{4}{|l|}{ POEM } \\
\hline Tunnel length $(\mathrm{cm})$ & $13.80 \pm 3.70$ & $13.36 \pm 1.99$ & 0.738 \\
\hline Myotomy length $(\mathrm{cm})$ & $12.20 \pm 3.11$ & $10.36 \pm 2.56$ & 0.208 \\
\hline \multicolumn{4}{|l|}{ After POEM } \\
\hline Total Eckardt scores & $3.20 \pm 0.75$ & $1.60 \pm 1.20$ & $0.010^{\mathrm{a}}$ \\
\hline GERDQ & $7(7-12)$ & $6(5-6)$ & $<0.01$ \\
\hline HRM variables & $\begin{array}{c}\text { Preoperative non-reflux and } \\
\text { postoperative reflux group }(n=3)\end{array}$ & $\begin{array}{c}\text { Preoperative non-reflux and } \\
\text { postoperative non-reflux group }(\mathrm{n}=5)\end{array}$ & $P$-value \\
\hline Length of esophageal $(\mathrm{cm})$ & $24.00(24.00-24.00)$ & $28.00(24.25-29.50)$ & 0.250 \\
\hline LESP (mmHg) & $34.60(17.40-34.60)$ & $10.80(5.60-27.35)$ & 0.143 \\
\hline $\operatorname{UESP}(\mathrm{mmHg})$ & $87.80(74.90-87.80)$ & $69.70(56.30-73.85)$ & 0.071 \\
\hline IRP (mmHg) & $19.00(14.60-19.00)$ & $9.70(4.25-16.45)$ & 0.143 \\
\hline$\triangle$ Eckardt scores & $1.50(-1.00-3.25)$ & $2.00(2.00-3.00)$ & 0.470 \\
\hline$\triangle \mathrm{LESP}(\mathrm{mmHg})$ & $9.60(-0.10-9.60)$ & $18.50(10.95-21.30)$ & 0.393 \\
\hline$\triangle \mathrm{IRP}(\mathrm{mmHg})$ & $12.20(7.30-12.20)$ & $18.60(13.15-24.15)$ & 0.250 \\
\hline
\end{tabular}

${ }^{\mathrm{a}} \mathrm{P}<0.05$.

BMI, body mass index; POEM, peroral esophageal myotomy; HRM, high-resolution manometry; LESP, lower esophageal sphincter pressure; UESP, upper esophageal sphincter pressure; IRP, integrated relaxation pressure; GERDQ, gastroesophageal reflux disease questionnaire; $\triangle$ Eckardt score $=$ preoperative Eckardt score - postoperative Eckardt score. $\triangle \mathrm{LESP}=$ preoperative LESP - postoperative LESP. $\triangle \mathrm{IRP}=$ preoperative IRP - postoperative IRP.

Values are presented as $\mathrm{n}$, median (interquartile range), mean $\pm \mathrm{SD}$, or $\mathrm{n}(\%)$.

subtypes. In our study, the reflux symptoms were not related to subtypes. In one study, type I patients had more reflux symptoms than type II patients, ${ }^{15}$ and in another study, the regurgitation score was higher in type II than type I in achalasia. ${ }^{10}$ The relationship between reflux symptoms and subtypes may still be controversial and needs more research.

Then, we compared the groups of postoperative symptoms. In our study, 25 of the 84 patients had postoperative reflux symptoms. Postoperative reflux symptoms did not equal the presence of pathological gastroesophageal reflux, the reason may be neurological dysfunction, long-term food retention, and esophageal clearance prob- lems. ${ }^{16}$ POEM tunnel length and myotomy length were similar between the reflux group and the non-reflux group after POEM. The LESP, IRP, and Eckardt scores after POEM were significant lower than those before POEM, which meant that POEM was successful and effective. In addition, the LESP and IRP after POEM were similar between the postoperative reflux group and non-reflux group, so the reflux symptoms should not be considered as a sign of LES excessive relaxation. The patients without reflux symptoms had greater reductions in LESP and Eckardt scores, and the patients with reflux symptoms after POEM had higher UES pressure. A study found that when food was accumulated 
in esophagus of patients with achalasia, as a result, the UES was contracted compensatorily in order to avoiding the food reflux while swallowing. ${ }^{17}$ After POEM, LESP decreased significantly. So the UES pressure may decrease. In our study, the patients with postoperative reflux symptoms had less reductions in LESP, this is why they had higher UES pressure. The greater reduction in LESP and the action of gravity could improve the food emptying, and the UES could relax.

In addition, we divided the patients with preoperative reflux symptoms into the group with postoperative reflux symptoms and the group without postoperative reflux symptoms. We also divided the patients without preoperative reflux symptoms into 2 groups, and we compared them separately. The general information, POEM information, LESP, and IRP were similar, this result reconfirmed that the reflux symptom after POEM was not a sign of LES excessive relaxation. The preoperative and postoperative values of LESP, IRP, and Eckardt scores did not have significant decline in patients who had reflux symptoms before POEM and with reflux symptoms after POEM, this may be related to the small patient population.

There were some limitations in our study. Our study was a retrospective and single center study, and a sufficient data could not be collected and hence there is bias. Also, the patient population is small, a larger sample study is required. Furthermore, $\mathrm{pH}$ test was not routinely performed after surgery, thus lacking support of objective data. In conclusion, the reflux symptoms of achalasia patients without treatment were mainly due to food retention. The reflux symptoms after POEM were not related to the reflux symptoms before POEM, and were not the signs of the excessive relaxation of LES. pH measurements are needed to confirm whether there is gastroesophageal reflux. Further research is needed.

Acknowledgements: We thank all participants in this research.

Financial support: This work was supported by the National Natural Science Foundation of China (Grant No. 81870378). The funder had no role in study design, data collection and analysis, decision to publish, or preparation of the manuscript.

\section{Conflicts of interest: None.}

Author contributions: Ying Xu was responsible for collecting data, analyzing, interpreting the data, and drafting the manuscript; Yan Wang and Yun Bao were responsible for collecting data, analyzing and interpreting the data; Ting Yu, Yurong Tang, and Lin Lin guided the designing; Liuqin Jiang was corresponding author and guarantor of the article, and was responsible for designing study, and editing and revising the draft. All authors critically approved the final version of the manuscript and agreed to the author list.

\section{References}

1. Vaezi MF, Pandolfino JE, Vela MF. ACG clinical guideline: diagnosis and management of achalasia. Am J Gastroenterol 2013;108:1238-1249.

2. Boeckxstaens GE, Zaninotto G, Richter JE. Achalasia. Lancet 2014;383:8393.

3. Vereczkei A, Bognár L, Papp A, Horváth ÖP. Achalasia following reflux disease: coincidence, consequence, or accommodation? An experience-based literature review. Ther Clin Risk Manag 2017;14:39-45.

4. Ponce J, Ortiz V, Maroto N, Ponce M, Bustamante M, Garrigues V. High prevalence of heartburn and low acid sensitivity in patients with idiopathic achalasia. Dig Dis Sci 2011;56:773-776.

5. Fisichella PM, Raz D, Palazzo F, Niponmick I, Patti MG. Clinical, radiological, and manometric profile in 145 patients with untreated achalasia. World J Surg 2008;32:1974-1979.

6. Shoenut JP, Micflikier AB, Yaffe CS, Den Boer B, Teskey JM. Reflux in untreated achalasia patients. J Clin Gastroenterol 1995;20:6-11.

7. Familiari P, Greco S, Gigante G, et al. Gastroesophageal reflux disease after peroral endoscopic myotomy: analysis of clinical, procedural and functional factors, associated with gastroesophageal reflux disease and esophagitis. Dig Endosc 2016;28:33-41.

8. Shiwaku H, Inoue $\mathrm{H}$, Sasaki T, et al. A prospective analysis of GERD after POEM on anterior myotomy. Surg Endosc 2016;30:2496-2504.

9. Jeon HH, Kim JH, Youn YH, Park H, Conklin JL. Clinical characteristics of patients with untreated achalasia. J Neurogastroenterol Motil 2017;23:378-384.

10. Tang Y, Xie C, Wang M, Jiang L, Shi R, Lin L. Association of highresolution manometry metrics with the symptoms of achalasia and the symptomatic outcomes of peroral esophageal myotomy. PLoS One 2015;10:e0139385.

11. Taft TH, Carlson DA, Triggs J, et al. Evaluating the reliability and construct validity of the Eckardt symptom score as a measure of achalasia severity. Neurogastroenterol Motil 2018;30:e13287.

12. Kahrilas PJ, Bredenoord AJ, Fox M, et al. The Chicago classification of esophageal motility disorders, v3.0. Neurogastroenterol Motil 2015;27:160-174.

13. Ling TS, Guo HM, Yang T, Peng CY, Zou XP, Shi RH. Effectiveness of peroral endoscopic myotomy in the treatment of achalasia: a pilot trial in Chinese Han population with a minimum of one-year follow-up. J Dig Dis 2014;15:352-358.

14. Meillier A, Midani D, Caroline D, Saadi M, Parkman H, Schey R. Difference of achalasia subtypes based on clinical symptoms, radiographic findings, and stasis scores. Rev Gastroenterol Mex 2018;83:3-8.

15. Min M, Peng LH, Yang YS, et al. Characteristics of achalasia subtypes in untreated Chinese patients: a high-resolution manometry study. J Dig Dis 2012;13:504-509. 
16. Jones EL, Meara MP, Schwartz JS, Hazey JW, Perry KA. Gastroesophageal reflux symptoms do not correlate with objective $\mathrm{pH}$ testing after peroral endoscopic myotomy. Surg Endosc 2016;30:947952.
17. Yao S, Linghu E. Peroral endoscopic myotomy can improve esophageal motility in patients with achalasia from a large sample self-control research (66 patients). PLoS One 2015;10:e0125942. 